Peer-Reviewed Article

ISSN: 2162-3104 Print/ ISSN: 2166-3750 Online

Volume 5, Issue 4 (2015), pp. 488-500

(c) Journal of International Students

http://jistudents.org

\title{
Knowledge, Education, and Attitudes of International Students to IELTS: A Case of Australia
}

\author{
Abe W Ata, PhD \\ Deakin University (Australia)
}

\begin{abstract}
The main objective of this study is to determine the knowledge, education and attitudes of Chinese, Indian and Arab speaking students in Australia towards the International English Language Testing System (IELTS) test. A questionnaire was administered to 200 students at six university language centers to investigate their overall response towards the four components of the IELTS test i.e. listening, reading, writing, and speaking. It was hypothesized that having positive or negative attitudes toward a certain language can exert considerable effect on the learners' performance on a language test. The effect of variables such as testing environment, test rubric, and broader demographic factors on attitudes of the three national groups were investigated. Significant differences were found on students' misconceptions of language learning, motivation and the degree to which it may have hindered their progress in attaining language skills.
\end{abstract}

Keywords: International students; IELTS test; Language and education; language attitudes

Although it is widely debated that students' attitudes towards a certain language proficiency test may affect their performance on that test, research on attitudes of these groups towards International English Language Testing System (IELTS ) is still absent. And crucially, how such attitudes might affect their overall band score in a standardized test such as IELTS is lacking. The purpose of this study is to investigate the relationship between Chinese, Indian and Arab IELTS candidates' knowledge, education and attitudes and their performance on IELTS and address significant gaps in this area of research study.

Much has been written about the IELTS methods of operations, validity of assessing the candidate readiness to move to higher education, and its contribution to the learning process in university environments (Coleman, Starfield, \& Hagaen, 2003). The current study extends the research further to focus on the benefits and drawbacks as perceived by three national groups: Chinese, Indian and Arab (Gulf region) candidates. Chinese and Gulf Arab learners are now the fastest growing group of international students in Australia (Marginson, 2011). Population increases, rapid economic growth, and strong aspirations of studying have all contributed to such 
an upsurge in studying IELTS in preparation for enrollments at accredited universities in both countries. Other reasons such as flexibility, affordability, reputation and accessibility to courses clearly play additional roles in attracting them to Australia (Marginson, 2011; Lo Bianco, 2005).

Holmes (1992) states that if people feel positive toward those who use the language, they would be more successful and also more highly motivated toward learning it. Van Lier (1996) claims that working with interesting and meaningful manifestations of language enhances motivation and positive attitudes to language and language learning

Consequently, one could assume that if second language learners initiate their language learning while they have negative attitudes towards the target language and the people using that language, they are not expected to make considerable progress in their process of language learning. This assumption was held as far back as 1995 when Truitt (1995) hypothesized that students' beliefs and attitudes about language learning may vary based on cultural background and previous experiences. Thus, it can be argued that positive or negative attitudes do not develop accidentally but have some reason for their emergence. Malallaha (2000) investigated the attitudes of Arab learners towards English and discovered that they have positive attitudes toward the English language and their proficiency in tests was positively related to their positive attitude to English. Hence, it can be argued that having positive or negative attitudes towards a certain language can exert considerable effect on the learners' performance on a language test.

Other studies on the relationships of causality summarized below are equally crucial. One study focuses on the relationship between IELTS preparation programs and candidates' performance in the actual IELTS test. Read and Hayes (2003) for instance, investigated the impact of IELTS preparation programs on international students' academic performance on tertiary study in New Zealand. Their study revealed that there were a number of substantial differences between the performance of the group which had undergone preparation programs and the group which had not. In 2007, Lewthwaite found, amongst UAE IELTS candidates, that the nature and type of activities used to prepare for their test was a major determinant of the balance of positive and negative attitudes. Others, like Elder and O'Loughlin (2003) investigated the relationship between intensive English language study and band score gain on IELTS. The results of their study revealed that students made variable progress in English during the three month period with an average gain of about half a band overall.

Attitudes that have been explored in relation to language learning range from anxiety about the language and the learning situation to attitudes towards speakers of the second language the country in which it is spoken, the classroom, the teacher, other learners, the nature of language learning, particular elements in the learning activities, tests and beliefs about learning in general (Johnson \& Johnson, 1998). According to Brown (2000), second language learners of English benefit from positive attitudes; negative attitudes may lead to decreased motivation. Nevertheless, he believes negative attitudes can be changed, often by exposure to reality - for example, by encounters with actual persons from other cultures.

Rasti (2009) found that candidates who have positive attitude towards IELTS do not differ from other groups in their performance on the test. Rasti concludes that merely having a high attitude towards this test does not guarantee gaining a good score and no formal study has shown this either. She notes that candidates should go through learning effective strategies to approach the test and attending IELTS preparation programs can be a good and effective step.

While students saw the benefits of having a speaking component to the exam, both felt high anxiety. This finding contrasted with those of Read and Hayes (2003) who report overall 'positive attitudes about IELTS amongst teachers and strong motivation amongst learners'. 
Merrylees (2003) conducted a study to investigate two IELTS user take groups: candidates who take the test for immigration purposes and candidates who sit the test for secondary education purposes. He believed that with the increase in candidature of both user groups, there is an increasing need to investigate and analyze how each group is performing on the test in terms of nationality, age, gender and other factors, instead of making a broad comparative analysis. Ata (2010) found that poor lexical or specific cultural knowledge of English by Arab-speaking students can cause several negative interferences. His study produces a significant recommendation - one which implies that IELTS preparation materials should include more texts and tasks that would contribute to the social and academic acculturation of students. Morgan Terry (2003) claims that the strong motivation and serious purposes of IELTS candidates is taken for granted. However, he believes that publishers need to respond more to the growing market for IELTS preparation and to start investing in colorful, attractive, motivating publications that can help promote learning for IELTS candidates in the way they have for students preparing for other exams.

The aims of this study are: to seek viewpoints of Chinese, Indian and Arab (Gulf) students in critically evaluating their attitudes, perceptions and knowledge of IELTS; and to reveal the effects of positive attitudes, or their-lack of, on the overall test results. Students at large have positive or negative attitudes towards the language they want to learn and the people who speak it. Having a positive attitude toward tests is also claimed to be one of the reasons why students perform better on the test (Malallaha, 2000). Studies that investigated the relationships between attitudes and proficiency in the language clearly show that attitudes and other affective variables are as important as aptitude for language achievement (see, Bayliss \& Ingram, 2006; Malallaha 2000; Coleman et al. 2003).

Since IELTS exams are now taken by candidates from over 170 countries, the rubric or the exam questions/essays should be as culture-free and as international as possible; and that where possible, culturally nuanced 'situated' contexts should be adapted to many IELTS rubrics. Lethwaite (2007), for example, found a strong overlap between what the IELTS writing tasks required and what UAE students and staff thought was needed in a writing course and that those who are really motivated and interested will read more widely. It might not be that the exam "encourages" such reading, he stressed, but it might mediate it or at least facilitate it. As regards the nature of the questions inviting personal opinion, some personal reflection on and prior assessment of various issues inevitably precede formulating a good written response.

This paper presents relevant evidence to support or refute these premises and fill in much needed gaps in the overall discussion about students' attitudes to IELTS. One of these premises is that IELTS developers engage in a research agenda that explores a range of international English language issues such as specific lexical or cultural knowledge that might disadvantage test takers. Another premise is that IELTS is not only a proficiency test to evaluate linguistic competence but it is also a comprehensive test which measures other components such as communicative competence.

\section{Research Method}

The unit of analysis was pre-test and post-test IELTS candidates. A structured questionnaire was administered to 200 Chinese, Arab and Indian students at the Monash, Melbourne and Deakin university language centers. The demographic information of participants includes: gendermale (134), female (106); religion orientation - Muslim (82), Hindu (4), Sikh (4), Buddhist (36), 
Christina (12), Other (102); origin of birth - Gulf (76), China (88), India (76); experience of living/studying in English speaking country - yes (88), no (152); languages spoken at home Arabic (56), Chinese (92), and other (92).

A structured questionnaire collects data underpinning the following themes: Appropriateness of taking the test; Demographic attributes of respondents; Areas of knowledge; Comparative effectiveness of IELTS versus other English tests; Attitudes to IELTS purpose and value; and Perceptions of test demands and outcome. The format of the questionnaire was largely, though not exclusively, adapted to Likert scale, as the candidates were asked to indicate their attitudes by choosing one of the three alternatives: Agree, Undecided, Disagree. Statistical methods included factor analysis with vairmax rotation, anova, analysis of variance, t-test, cross tabulation and Pearson's correlation.

\section{Findings and Discussion}

The findings show that with the exception of the variable "the surroundings such as lighting, temperature, floor, desks that affected my performance," variations in the response by the three cohorts were highly significant with the exception of the variable "the surroundings such as lighting, temperature, floor, desks that affected my performance." It is also shown that Chinese students exhibit the strongest expression on all the variables except the following two for which Arabs students from the Gulf Region took the lead. These were:

- I prefer IELTS to other English Language tests

- I I found the announcements and administration of the text itself distracting

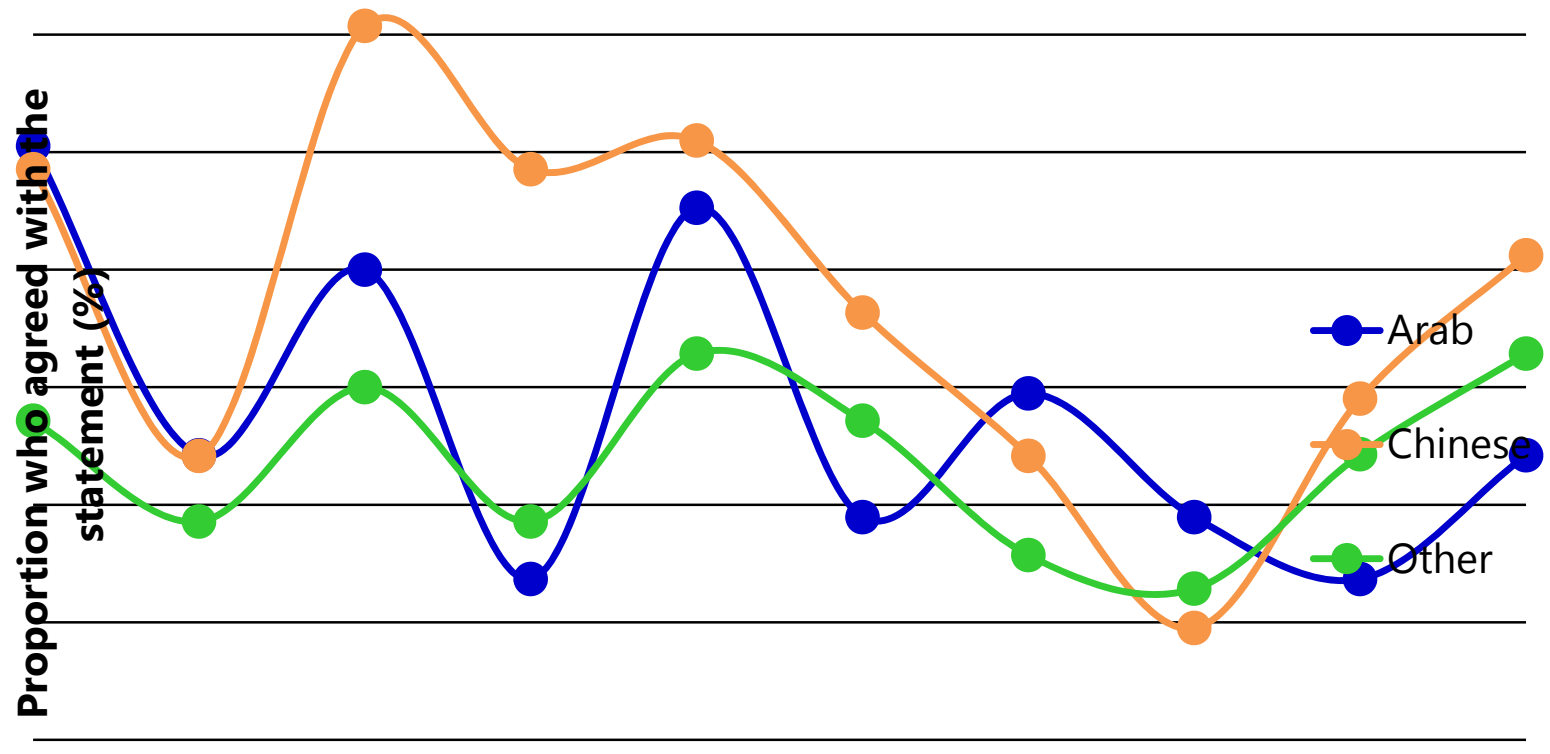

Figure 1. General attitudes to IELTS 
General attitudes to IELTS: statements and significance (computation includes non-response adjustment)

perform = Fear of taking the IELTS test affected my performance

$X^{2}(9, N=240)=19.15, p=.024$

Surround $=$ The surroundings such as lighting, temperature, floor, desks affected my performance $X^{2}(9, N=240)=19.15, p=.443$

time $=$ The time of taking the IELTS test affected my performance $X^{2}(9, \mathrm{~N}=240)=19.15, \mathrm{p}=.013$

Families $=$ Being familiar with the place where I took the IELTS test helped my performance

$X^{2}(9, \mathrm{~N}=240)=19.15, \mathrm{p}=.00$

familiar= Being familiar with the design, structure and format of the test helped my

performance $X^{2}(9, \mathrm{~N}=240)=19.15, \mathrm{p}=.005$

Attit $=$ My attitude to IELTS test is largely positive $X^{2}(9, \mathrm{~N}=240)=19.15, \mathrm{p}=.004$

Pref $=$ I prefer IELTS to other English Language tests X2(9,N=240)=19.15,p=.042

Distract $=\mathrm{I}$ found the announcements and administration of the text itself distracting

$X^{2}(9, \mathrm{~N}=240)=19.15, \mathrm{p}=.026$

Limit $=$ In my country our socio-cultural experience such as the freedom of the press, limits

my ability in performing well in the IELTS tests. $X^{2}(9, \mathrm{~N}=240)=19.15, \mathrm{p}=.018$

Critical = In my country students are not encouraged to develop critical thinking as in Australia.

$X^{2}(9, \mathrm{~N}=240)=19.15, \mathrm{p}=.016$

Chinese cohort indicated a positive feel in performing well. They registered the highest response in not being encouraged to develop critical thinking in Australia, and their ability to perform well is hampered by the socio-cultural experience in their own country. Arab students indicated the lowest response in the following items: My attitude to IELTS test is largely positive; Being familiar with the place where I took the IELTS test helped my performance; In my country our socio-cultural experience such as the freedom of the press, limits my ability in performing well in the IELTS tests; In my country students are not encouraged to develop critical thinking as in Australia.

Indian cohort participants indicated the lowest dislike in the following items: Fear of taking the IELTS test affected my performance; The surroundings such as lighting, temperature, floor, desks affected my performance; The time of taking the IELTS test affected my performance; Being familiar with the design, structure and format of the test helped my performance; I prefer IELTS to other English Language tests; In my country our socio-cultural experience such as the freedom of the press, limits my ability in performing well in the IELTS tests; In my country students are not encouraged to develop critical thinking as in Australia.

The negative association between gender and the response to these two statements was not significant. The suggestion being that both male and female international students are equally impacted in terms of showing a better performance.

\section{Listening Section}

Figure 2 present responses to what Chinese students disliked about the Listening section of IELTS: Tempo or speed (60\%); Responding at the same time while listening (44\%); Performance deteriorated as the test moved forward (54\%); Not enough time for the answers to be transferred to the answer sheet from the question booklet (47\%); Test does not really evaluate listening comprehension (45\%); the test being not useful for their future studies” (11\%). 
It is not possible to make a conclusive statement explaining this variation. One may reason that being socialized in a traditional society may have contributed to being more restrained in mixing with genders of other nationalities - English speaking or otherwise. Frequenting movies and other Australian cultural-social events, eateries and the like, particularly in evening hours provide a wider exposure and accessibility to spoken English. Another factor is related to international students from the same background tend to live together in preference to renting in family households where they are less likely to communicate in English.

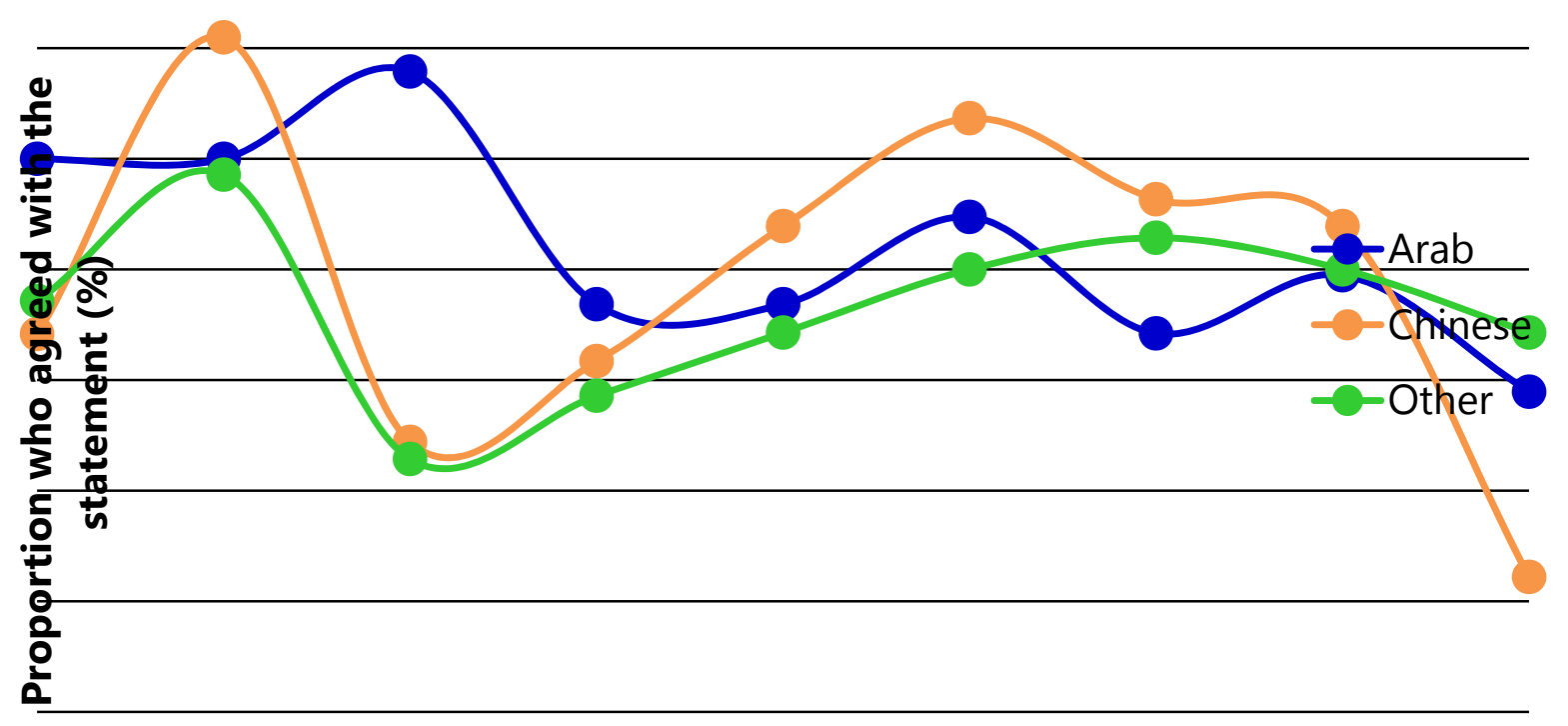

Figure 2. Attitudes to the Listening Section

Attitudes to the Listening Section: Statements and significance (computation includes nonresponse adjustment)

$$
\begin{aligned}
& \text { Ldislike1 = Non-familiarity Australian accent } X^{2}(9, N=240)=19.15, p=.070 \\
& \text { Ldislike2 }=\text { tempo or speed } \quad X^{2}(9, \mathrm{~N}=240)=19.15, \mathrm{p}=.038 \\
& \text { Ldislike3 = lack of opportunity to wear headphones } X^{2}(9, \mathrm{~N}=240)=19.15, \mathrm{p}=.000 \\
& \text { Ldislike4 = poor quality of the voice } X^{2}(9, \mathrm{~N}=240)=19.15, \mathrm{p}=.0379 \\
& \text { Ldislike5 = Responding at the same time whilst listening. } X^{2}(9, \mathrm{~N}=240)=19.15, \mathrm{p}=.726 \\
& \text { Ldislike6 = Performance deteriorated as the test moved forward } X^{2}(9, \mathrm{~N}=240)=19.15, \mathrm{p}=.357 \\
& \text { Ldislike7 = Not enough time for the answers to be transferred to the answer sheet from the } \\
& \text { question booklet } X^{2}(9, \mathrm{~N}=240)=19.15, \mathrm{p}=.226 \\
& \text { Ldislike8 = Test does not really evaluate listening comprehension } \left.X^{2}(9, \mathrm{~N}=240)=19.15, \mathrm{p}=.640\right) \\
& \text { Ldislike9 = Test is not useful for my future studies } X^{2}(9, \mathrm{~N}=240)=19.15, \mathrm{p}=.003
\end{aligned}
$$

\section{Reading Section}

Students showed mixed feelings recognizing that their reading section pushed them hard but it was not accurate in mirroring their study of being relevant to their study needs in the future. The statement the "Test is not useful for my future studies" drew the lowest response from the three cohort groups combined, with Chinese students scoring the lowest response at $11 \%$, followed by the Arab group at $28 \%$ and Indians at $35 \%$. 
A higher percentage of 50\% for the Chinese and Arab speaking and 70\% for "Other" did not see any benefits in "reading a lot of English texts before the exam". These largely mixed negative feelings arising from working hard but not accurate mirroring their study needs (Spratt, 2005).

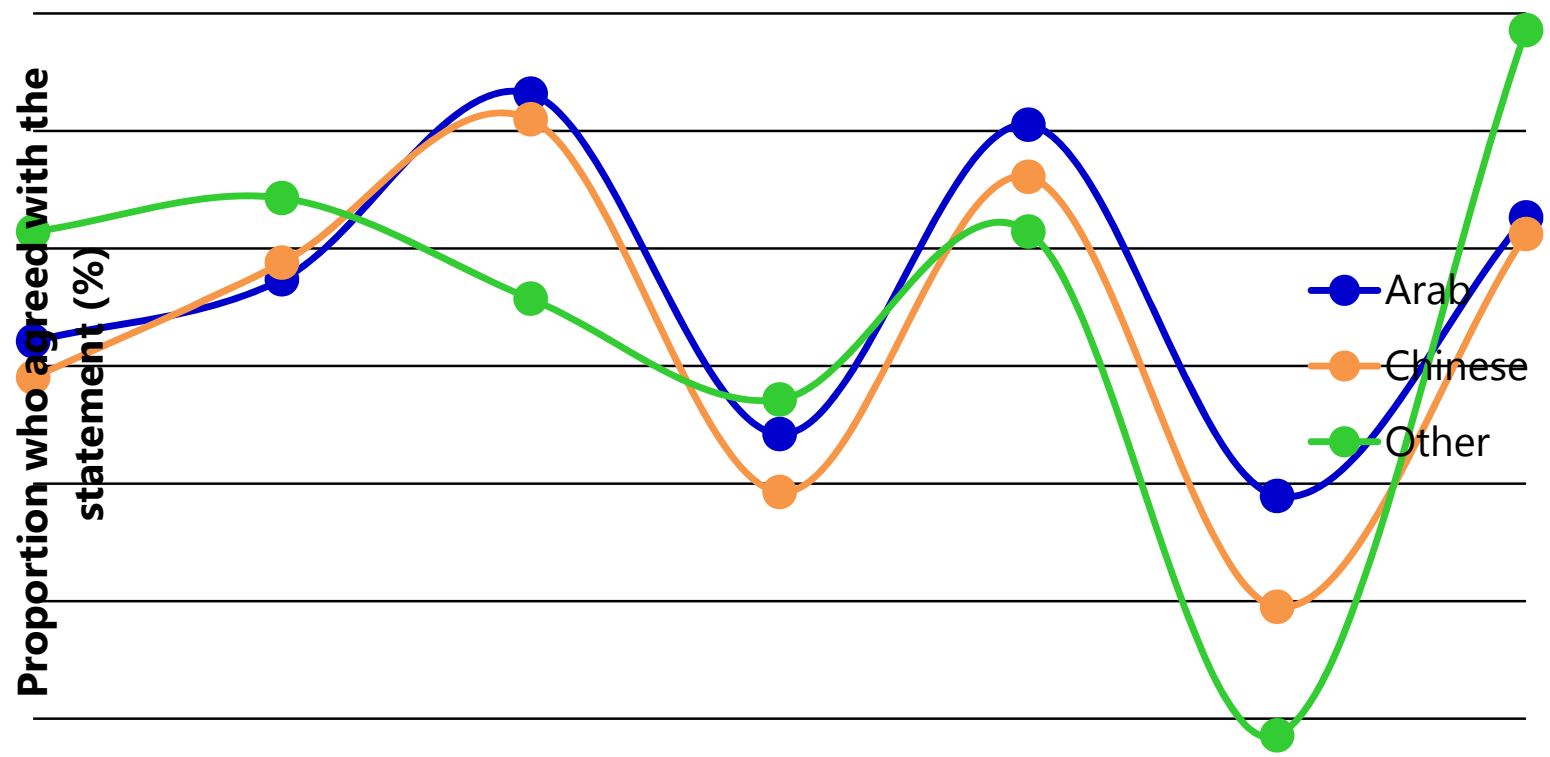

Figure 3. Attitudes to the Reading Section

Attitudes to the Reading Section: Statements and significance (computation includes nonresponse adjustment)

Rdislike1 = Reading is immediately after listening $\quad X^{2}(9, \mathrm{~N}=240)=19.15, \mathrm{p}=.0 .111$

Rdislike2 = Disliked the variety of question types $X^{2}(9, \mathrm{~N}=240)=19.15, \mathrm{p}=.0 .258$

Rdislike3 = Lengthy passages $\quad X^{2}(9, \mathrm{~N}=240)=19.15, \mathrm{p}=.0 .084$

Rdislike4 = Test is not useful for my future studies $X^{2}(9, \mathrm{~N}=240)=19.15, \mathrm{p}=.0 .214$

Rdislike5 = Texts became more difficult towards the end of the reading section

$X^{2}(9, \mathrm{~N}=240)=19.15, \mathrm{p}=.0 .367$

Rdislike6 = Knowledge of vocabulary and grammar is not important

$X^{2}(9, \mathrm{~N}=240)=19.15, \mathrm{p}=.0 .016$

Rdislike7 = Reading a lot of English texts before the exam $\quad X^{2}(9, \mathrm{~N}=240)=19.15, \mathrm{p}=.0 .001$

\section{Writing Section}

Several variables were introduced to assess the reasons and degree behind the dislike for the Writing Section. The two main groups who recorded the highest dislike to the first four variables are the Chinese and Arabic speaking. The limitation or lack of knowledge of the world or information related to a given topic (variable Dislike4) clearly shows that different 
dimensions of assessment of literacy may need to be prioritized a) for different disciplines, such as language testing, where knowledge of what it means to know and use a language is surely essential, b) within particular academic and professional domains, where language requirements may vary, and c) with particular users such as students, parents, school administrators, teachers, or test developers whose needs for and uses of information are highly diverse depending the nature and the level of their involvement in the assessment process (Taylor, 2009).

None of the variables in this section were significant with the exception of Wdislike5 = being given more than one task (sig, .0013).

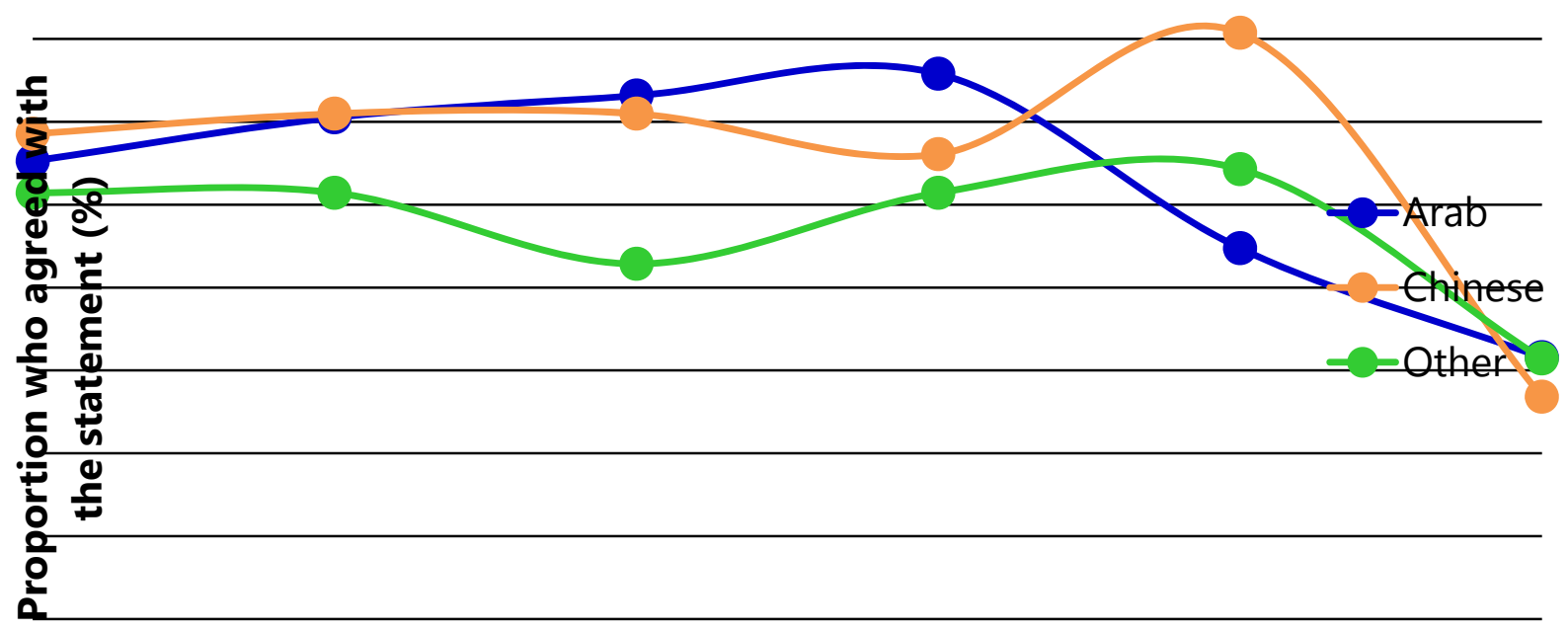

Figure 4. Attitudes to the Writing Section

Attitudes to the Writing Section: statements and significance (computation includes non-response adjustment)

Wdislike 1 =Tired in this section because of their performance on the first two sections.

$X^{2}(9, \mathrm{~N}=240)=19.15, \mathrm{p}=.0 .362$

Wdislike2 = lengthy topics cause difficulty in concentration $X^{2}(9, \mathrm{~N}=240)=19.15, \mathrm{p}=.0 .281$

Wdislike $3=$ knowledge of vocabulary and grammar is crucial in this section

$X^{2}(9, \mathrm{~N}=240)=19.15, \mathrm{p}=.0 .077$

Wdislike4 = not enough knowledge of the world or information related to the given topic

$X^{2}(9, \mathrm{~N}=240)=19.15, \mathrm{p}=0.056$

Wdislike5 = being given more than one task $\quad X^{2}(9, \mathrm{~N}=240)=19.15, \mathrm{p}=.0 .013$

Wdislike6 $=$ test is not useful for my future studies $X^{2}(9, \mathrm{~N}=240)=19.15, \mathrm{p} .=.288$

This greater focus on assessment brings with it the need for assessment literacy, defined variously as having the skills needed for test development and validation, the knowledge required to make informed an principled score-based decision-making, and the ability to read and make sense of assessment-related research data (Newfields, 2006).

Other language educators like Lewthwaite believe that the writing task is "nonacademic" in the sense that a personal opinion was asked for and respondents are not able to, and not expected to, draw upon empirical evidence, statistical data or the academic expertise of published material. (2007, p. 8). This would explain why Arabic speaking candidates in 
particular scored highest (65\%) on the variable 'Wdislike4' that there was 'not enough knowledge of the world or information related to the given topic' - a common observation made about school curriculum and rote learning styles in schools in the Middle Eastern countries.

AAs Lewthwaite's (2007) experience in teaching IELTS to UAE students shows, 'IELTS tests had more limited rhetorical functions (an emphasis on hortatory at the expense of other functions such as explanation, comparison, summarization) and focused much more on 'real world' contexts compared with the greater emphasis on abstract ideas in university tasks. Although written in 1999, an article by Moore and Morton suggested that Task 2 'may be more akin to public non-academic genres (newspapers, magazines) than characteristic of university assignments' (see also Lewthwaite (2007).

Several students mentioned the unrealistic time limit of (recommended) 20 minutes for the exam task cause difficulty on concentrating on lengthy topics (Figure 4, variable Wdislike2). This reaction was corroborated by $60 \%$ of Arabic speaking and Chinese candidates and $50 \%$ 'Other'. The response of these groups to being given more than one task in a short time was almost the same (Figure 4, Wdislike5). While it might reflect one type of university writing writing exams under time constraints - it was unclear whether this was helpful to another major form of university writing, that of research activity,

\section{Speaking Section}

The direction of the results for the Speaking part is more pronounced than the Writing part. That is, feedback about difficulties experience in the Speaking section was stronger, varied and more pronounced than the Writing part. The Chinese cohort in particular ranked highest on the following three statements:

- (Sdislike4) Having stress or lacking confidence at the time of interview.(75\%)

- (Sdislike5) Being asked too many questions in rather a short time (48\%)

- (Sdislike3) Interviewer's accent (67\%).

The Indian group ranked lower and the Arab candidates ranked the lowest on these statements.

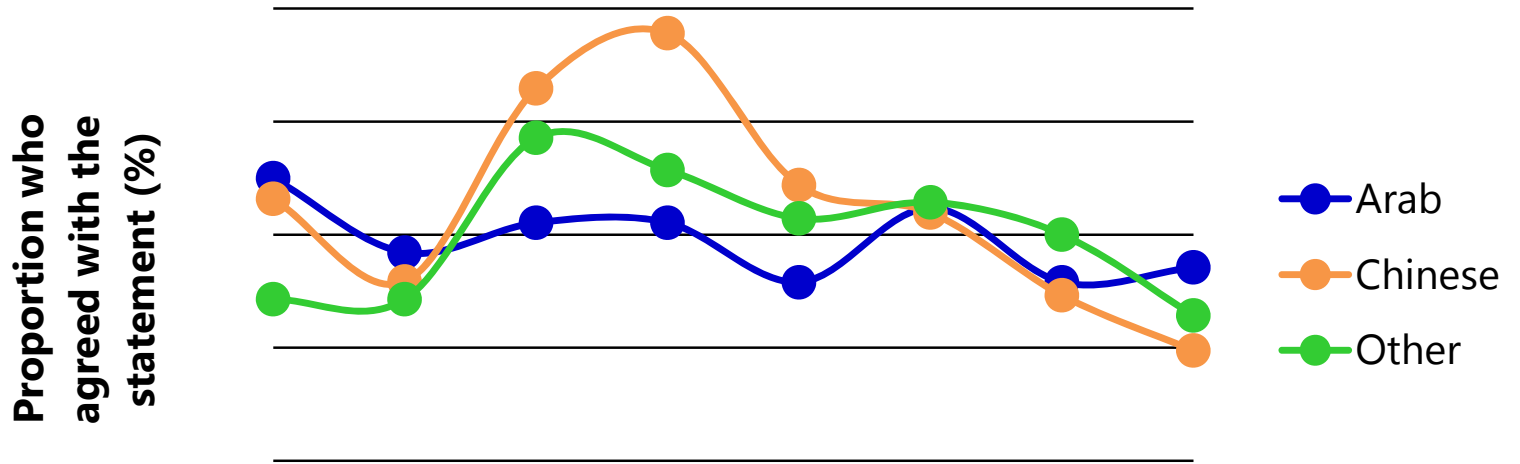

Figure 5. Attitudes to the Speaking Section 
Attitudes to the Speaking Section: Statements and significance (computation includes nonresponse adjustment)

Sdislike1 $=$ The examiner's gender affected their performance. $X^{2}(9, \mathrm{~N}=240)=19.15,=\mathrm{p} 0.056$. Sdislike2 $=$ Test examines one's listening ability, not one's speaking ability.

$X^{2}(9, \mathrm{~N}=240)=19.15, \mathrm{p}=.0 .268$

Sdislike3 = Interviewer's accent $X^{2}(9, \mathrm{~N}=240)=19.15, \mathrm{p}=.0 .005$

Sdislike $4=$ Having stress or lacking confidence at the time of interview.

$X^{2}(9, \mathrm{~N}=240)=19.15, \mathrm{p}=.0 .000$

Sdislike5 $=$ Being asked too many questions in rather a short time.

$X^{2}(9, \mathrm{~N}=240)=19.15, \mathrm{p}=.0 .064$

Sdislike6 = Being recorded would add to their test anxiety $X^{2}(9, \mathrm{~N}=240)=19.15, \mathrm{p}=0.228$

Sdislike7 $=$ The questions in this section were not related to each other.

$X^{2}(9, \mathrm{~N}=240)=19.15, \mathrm{p}=0.061$

Sdislike8 $=$ The test is not useful for my future studies $X^{2}(9, \mathrm{~N}=240)=19.15, \mathrm{p}=.0 .080$

Another difference that affected performance amongst the three groups relates to the gender of the examiner with 50\% Arabs, 48\% Chinese and 29\% Indians indicating agreement that the examiner's gender affected their performance. Such a relatively high response in an exam environment is not easy to explain notwithstanding calculation for a level of significance. One linguist surmised that that the teacher, male and female alike, "is placed in the driver's seat - a position of primary influence in terms of the teacher beliefs, attitudes, educational level and experience, and personalities” (Spratt, 2005, p. 17-23).

Other factors that may contribute to this finding are: lack of motivation, so if the learners do not want to interact, they will not; and insufficient language, so if the learners do not have enough English language, it will be difficult for them to interact (Howarth, 2006).

\section{Conclusions}

While the above findings are preliminary, there appears to be two broad attitudes underpinning these findings: the first is widespread acceptance of the quality of the language tests used for selection as well as satisfaction with and trust in the information provided.

Several variables were introduced to assess the reasons and degree behind disliking the Writing Section. The two main groups who recorded the highest dislike to the first four variables are the Chinese and Arabic speaking. The limitation or lack of knowledge of the world or information related to a given topic (variable Dislike4) clearly shows that different dimensions of assessment of literacy may need to be prioritized a) for different disciplines, such as language testing, where knowledge of what it means to know and use a language is surely essential, b) within particular academic and professional domains, where language requirements may vary, and c) with particular users such as students, parents, school administrators, teachers

It has been proposed that Learning contexts and familiarity information and issues lead to a greater fluency and accuracy in performing English Language tests (Mehnert, 1998). If that premise holds true then writings task related to women's issues, questioning parental attitudes, organ donation, freedom of thinking and rote memory learning at school and the like would disadvantage students from traditional cultures. The constrains of how the spontaneity of addressing these task mirror task requirements later on in tertiary institutions requires further 
investigation. The direction of the results for the Speaking part is more pronounced than the Writing part. That is, feedback about difficulties experience in the Speaking section was stronger, varied and more pronounced than the Writing part.

Students showed mixed feelings recognizing that the Reading section pushed them hard but it was not accurate in mirroring their study of being relevant to their study needs in the future. The statement the "Test is not useful for my future studies" drew the lowest response from the three cohort groups combined, with Chinese students scoring the lowest response at $11 \%$, followed by the Arab group at $28 \%$ and Indian at $35 \%$.

As regards the unfavorable attitudes to the listening section, one may reason that being socialized in a traditional society may have contributed to being more restrained in mixing with genders of other nationalities - English speaking or otherwise. Frequenting movies and other Australian cultural-social events, eateries and the like particularly in evening hours provide a wider exposure and accessibility to spoken English. Another factor is related to international students from the same background to live together in preference to renting in family households where they are less likely to communicate in English.

This survey has raised a number of questions aimed at areas that require further probing. Of significance are the following: Is there a principled basis for the setting of minimum entry standards and whether the current cut off scores are appropriate? Is there a need to address the lack of systematic data collection to evaluate their [entry standards] appropriateness and, by extension the rationale of determining that language test scores are the basis for selection decisions? Why do IELTS stakeholder continue to make little reference to other relevant factors which might have a bearing on students' chances of academic success? And, does achieving the specified minimum IELTS score imply that students' English proficiency is sufficient to successfully complete rather than commence their courses?

On the basis of the overall response for this section, one could safely surmise that the relative acceptance and trust in what benefits students will gain as a consequence are not to be underestimated. This, however, does not translate into a general understanding of or interest in language proficiency test content, scoring procedures, cut-off scores and cross-test equivalences or associated validity evidence, as perceived by the respondents to meet their needs.

The broader response to several questions relating to core issues surrounding IELTS remains inconclusive. Questions relating to bilingual and English language learning by international students have been raised by numerous researcher including Dooey (2010) and Lasagabasete, (2008).

There is a deep division, for example, in the view as to whether current cut off scores are appropriate. Others raise questions behind the principled basis for the setting of minimum entry standards; and why is there an overemphasis on language test scores as the basis for selection decisions based on language test scores without reference to other relevant factors which might have a bearing on students' chances of academic success? And lastly "does achieving the specified minimum IELTS score imply that students' English proficiency is sufficient to successfully complete rather than commence their courses!"

These conclusions are largely subject to a number of caveats. The findings, for example, apply to particular cohort groups in a particular learning social context - one where to extent of its applicability to other groups in other contexts is unknown. Another obvious limitation shows that self-reporting almost always becomes embedded in the analysis of the data itself. It also seems important to test for the degree to which the developers of language tests may 
communicate complacency about their own levels of expertise and understanding about the qualities of tests, the meaning of test scores and the informational needs in these contexts.

In order to test for a high predictive validity of the nature of IELTS test score in relation to university requirements of acceptable language proficiency, this study needs to be extended further to include perception of teachers themselves. How the two groups, educators and students differ in their attitudes, would accurately indicate the relationship between the language skills reflected in IELTS scores and abilities required by the universities to succeed.

The chasm between how staff and students may differ in their perception of predictive nature of IELTS test scores in determining the languages abilities at tertiary institutions was widely demonstrated in one of the IELTS Research Reports by Coleman and others (2003).

NOTE -This research was supported by Deakin University and William Angliss Charitable Fund (Victoria)

\section{REFERENCES}

Ata, A. W. (2010). Grammatical interference from Arabic to English can pose big challenges for students. E l gazette (Britain), 4, 2 -23.

Bayliss, A., \& Ingram, A.(2006). IELTS as a Predictor of Academic Language Performance. Australian International Education Conference, 1-12.

Coleman, D., \& Strafield, S., \& Hagan, A. (2003). The attitudes of IELTS stakeholders: Student and staff apperception of IELTS in Australian, UK, and Chinese tertiary institutions. IELTS Australia Research, 5, 20-34.

Dooey, P. (2010). Students' perspectives of an EAP pathway program. Journal of English for Academic Purposes, 9(4), 184-197.

Elder, C., \& O’Loughlin, K. (2003). Investigating the relationship between intensive English language study and band score gain on IELTS. IELTS Australia Research, 4, 82-93.

Holmes, J. (1992). An introduction to sociolinguistics. London: Longman.

Howarth, P. (2006). Increasing student interaction. Retrieved from www.teachingenglish.org.uk/think/speak/interaction.shtml

Lewthwaite, M. (2007)). Teacher and Student Attitudes to IELTS writing tasks: positive or negative washback? Action Research Report, UGRU Journal, 5, 1-23.

Lo Bianco, J. (2005). Asian Languages in Australian Schools: Policy Options, Melbourne. Asia Policy Papers 7, University of Melbourne, Australia.

Marginson, S. (2011). Global position and position taking: The case of Australia. Education Dynamics, 36, 375-392.

Merrylees, B. (2003). An impact study of two IELTS user groups: Candidates who sit for the immigration purposes and candidates who sit for secondary education purposes.

IELTS Australia Research, 4, 27-39.

Moore, T., \& Morton, J. (1999). Authenticity in the IELTS academic module writing test: A comparative study of task 2 items and university assignments. IELTS Review, 2.

Rasti, I. (2009). Iranian candidates' attitudes towards IELTS. Asian EFT Journal, 11(3), 5.

Read, J., \& Hayes, B. (2003). The impact of IELTS on preparation for academic study in New Zealand. In R. Tulloh (Ed.), IELTS Research Reports, 4, 153-205.

Spratt, M. (2005). Washback and the classroom: the implications for teaching and learning of studies of washback from exams. Language Teaching Research, 9(1), 5-29. 
Taylor, L. (2009). Developing assessment literacy. Annual Review of Applied Linguistics, 29, 21-26.

Terry, M. (2003). IELTS Preparation Materials. ELT Journal, 57(1), 66-76.

Truitt, H. (1995). Beliefs about language learning: A study of Korean University students learning English. Texas Papers in Foreign Language Education,2,12-28.

Van Lier, L. (1996). Interaction in the language curriculum: Awareness: Autonomy and authenticity. London: Longman.

Yeh, C., \& Inose, M.(2003). International students reported English fluency, social support satisfaction, and social connectedness as predictors of acculturative stress. Counselling Psychology Quarterly, 16(1), 15-28

Yao, L. (2004). The Chinese overseas students: An overview of the flows change. Paper presented at 12 Biennial Conference, The Australian National University, Australian Population Association, Australian National University, Canberra, 15-17 September, $1-25$.

\section{AUTHOR}

ABE W. ATA was born in Bethlehem. He graduated in social psychology at the American University and was soon nominated as a delegate to the United Nations' World Youth Assembly. He gained his doctorate at the University of Melbourne in 1980 and has since been teaching and researching at several Australian, American, Jordanian, West Bank (Al-Quds) and Danish universities. He has worked at the Australian Catholic University for several years. His publications span 114 journal articles and 16 books including International education and cultural-linguistic experiences of international students in Australia (Australian Academic Press, June 2015); Education Integration Challenges: The case of Australian Muslims (Dec.2013); Us and Them (Australian Academic Press) which was nominated for the Prime Minister Book Awards in 2009; and Christian-Muslim Intermarriage in Australia (2003) Dr. Ata contributed several articles to the Encyclopedia of Australian Religions (2009); Encyclopedia of the Australian People (2001) and The Encyclopedia of Melbourne (2005). He was nominated as Australian of the Year in 2015 and 2011. Dr. Ata is currently an Honorary Fellow at Deakin University. 